\title{
Quantitative T1 $\rho$ MRI of the Head and Neck Discriminates Carcinoma and Benign Hyperplasia in the Nasopharynx
}

\author{
(D) Q.Y.H. Ai, (D)W. Chen, (D)T.Y. So, (DW.K.J. Lam, (D) B. Jiang, (DD.M.C. Poon, (D) S. Qamar, (D)F.K.F. Mo, (D)T. Blu, (D). Chan,
} (D)B.B.Y. Ma, (DE.P. Hui, (D) K.C.A. Chan, and (D)A.D. King

\begin{abstract}
BACKGROUND AND PURPOSE: Tl $\rho$ imaging is a new quantitative MR imaging pulse sequence with the potential to discriminate between malignant and benign tissue. In this study, we evaluated the capability of $\mathrm{Tl} \rho$ imaging to characterize tissue by applying Tl$\rho$ imaging to malignant and benign tissue in the nasopharynx and to normal tissue in the head and neck.
\end{abstract}

MATERIALS AND METHODS: Participants with undifferentiated nasopharyngeal carcinoma and benign hyperplasia of the nasopharynx prospectively underwent $\Pi \rho$ imaging. $\Pi \rho$ measurements obtained from the histogram analysis for nasopharyngeal carcinoma in 43 participants were compared with those for benign hyperplasia and for normal tissue (brain, muscle, and parotid glands) in 41 participants using the Mann-Whitney $U$ test. The area under the curve of significant $\Pi \rho$ measurements was calculated and compared using receiver operating characteristic analysis and the Delong test, respectively. A $P<.05$ indicated statistical significance.

RESULTS: There were significant differences in $\mathrm{Tl} \rho$ measurements between nasopharyngeal carcinoma and benign hyperplasia and between nasopharyngeal carcinoma and normal tissue (all, $P<.05$ ). Compared with benign hyperplasia, nasopharyngeal carcinoma showed a lower $\mathrm{T} 1 \rho$ mean (62.14 versus $65.45 \times \mathrm{ms})$, SD (12.60 versus $17.73 \times \mathrm{ms}$ ), and skewness (0.61 versus 0.76$)$ (all $P<.05)$, but no difference in kurtosis $(P=.18)$. The Tl $\rho$ SD showed the highest area under the curve of 0.95 compared with the Tl $\rho$ mean (area under the curve $=0.72$ ) and $\mathrm{Tl} \rho$ skewness (area under the curve $=0.72$ ) for discriminating nasopharyngeal carcinoma and benign hyperplasia (all, $P<.05$ ).

CONCLUSIONS: Quantitative Tl $\rho$ imaging has the potential to discriminate malignant from benign and normal tissue in the head and neck.

ABBREVIATIONS: $\mathrm{AHP}=$ adiabatic half passage; $\mathrm{AUC}=$ area under the curve; NPC = nasopharyngeal carcinoma; $r$ AHP = reverse adiabatic half passage; TSL $=$ time of spin-lock; PSNR = peak signal-to-noise ratio

T he spin-lattice relaxation time in the rotating frame known as $\mathrm{T} 1 \rho$ is sensitive to biologic processes associated with alterations in the macromolecular content of tissue. Quantitative T1 $\rho$ imaging has been used to study normal tissue and nonmalignant diseases in cartilage, discs, and ligaments, ${ }^{1-3}$ brain, ${ }^{4-7}$ liver,${ }^{8,9}$ heart, ${ }^{10}$ muscles, ${ }^{11}$ and parotid glands. ${ }^{11-13}$ However, T1 $\rho$ imaging also has the potential to characterize benign and malignant processes, but only a few studies have preliminarily evaluated $\mathrm{T} 1 \rho$ for human cancer

Received January 16, 2020; accepted after revision August 7.

From the Department of Imaging and Interventional Radiology (Q.Y.H.A., W.C., T.Y.S., B.J., S.Q., A.D.K.), Li Ka Shing Institute of Health Sciences (W.K.J.L., D.M.C.P., B.B.Y.M., E.P.H., K.C.A.C.), Department of Clinical Oncology (D.M.C.P., F.K.F.M., B.B.Y.M., E.P.H.), State Key Laboratory in Oncology in South China, Sir Y.K. Pao Centre for Cancer, The Chinese University of Hong Kong, Prince of Wales Hospital, Hong Kong, SAR; State Key Laboratory of Translational Oncology (W.K.J.L., D.M.C.P., F.K.F.M., B.B.Y.M., E.P.H., K.C.A.C.) and Department of Electrical Engineering (T.B.), The Chinese University of Hong Kong, Hong Kong, SAR; Department of Chemical Pathology (W.K.J.L., K.C.A.C.), State Key Laboratory in Oncology in South China, Li Ka Shing Institute of Health Sciences, The Chinese University of Hong Kong, Shatin, New Territories, Hong Kong, SAR; and Philips Healthcare (Q.C.), Hong Kong, SAR.; and imaging. These studies showed differences of T1 $\rho$ values between high- and low-grade gliomas ${ }^{14}$ and between benign and malignant tissue in the brain, ${ }^{15,16}$ breast, ${ }^{17}$ and prostate. ${ }^{18}$

We are interested in quantitative MR imaging sequences that can be used to discriminate nasopharyngeal carcinoma (NPC) from benign hyperplasia in the nasopharynx because these entities may overlap on anatomic MR imaging sequences. ${ }^{19,20}$ Our hypothesis is that the T1 $\rho$ value of malignancy is different from that of benign tissue and can be used to discriminate these 2 entities. In this preliminary study, we also applied $\mathrm{T} 1 \rho$ imaging to a

Paper previously presented, in part, at: European Society Head and Neck Society Refresh, October 3-5, 2019; Sicily, Italy.

Please address correspondence to Weitian Chen, PhD, Department of Imaging and Interventional Radiology, Faculty of Medicine, The Chinese University of Hong Kong, Prince of Wales Hospital, 30-32 Ngan Shing St, Shatin, New Territories, Hong Kong, SAR; e-mail: wtchen@cuhk.edu.hk

Indicates article with supplemental on-line tables.

http://dx.doi.org/10.3174/ajnr.A6828 
range of normal tissue in the head and neck (brain, pterygoid muscle, and parotid gland) to compare the T1 $\rho$ values of normal tissue with those of NPC.

\section{MATERIALS AND METHODS \\ Participants}

This prospective study was performed with local institutional board approval. Written informed consent was obtained from ethnically Chinese participants who underwent MR imaging between September 2018 and August 2019 in the Prince of Wales Hospital, Hong Kong, SAR.

Participants with NPC had newly diagnosed biopsy-proved undifferentiated carcinoma and a primary tumor of $>5 \mathrm{~mm}$. The primary tumor was staged according to the 8th edition of the AJCC Cancer Staging Manual. ${ }^{21}$ Participants with benign hyperplasia had been referred for MR imaging for suspected NPC because of persistently raised plasma Epstein-Barr virus DNA and benign hyperplasia of $>5 \mathrm{~mm}$ on MR imaging without evidence of NPC on MR imaging, endoscopic examination, and clinical follow-up at a minimum of 6 months.

\section{MR Imaging Acquisition}

MR imaging was performed with an Achieva TX 3T scanner (Philips Healthcare). T1 $\rho$ imaging was performed using an adiabatic continuous wave constant amplitude spin-lock approach, ${ }^{22}$ followed by a single-shot turbo spin-echo acquisition. Fat signal was suppressed using spectral attenuated inversion recovery. The spinlock radiofrequency pulse cluster consisted of a constant amplitude spin-lock radiofrequency pulse sandwiched by an adiabatic half passage (AHP) and a reverse adiabatic half passage (rAHP). Hyperbolic secant pulses were used as the AHP and rAHP with the $\mathrm{B}_{1}$ amplitude of the AHP and rAHP set equal to that of the spin-lock radiofrequency pulse. ${ }^{22,23}$ Details of the pulse sequence are reported previously, ${ }^{24}$ but in summary, the imaging parameters were the following: TR/TE, 2500/15 ms; FOV, $230 \times 216 \mathrm{~mm}$; resolution, $1.2 \times$ $1.2 \mathrm{~mm}$; section thickness, $4 \mathrm{~mm}$; number of slices, 9; sensitivity encoding factor, 2; AHP and rAHP duration, $25 \mathrm{~ms}$; maximum amplitude of frequency waveform modulation of the AHP and rAHP, $400 \mathrm{~Hz}$; coefficient factor $\beta$ for AHP and rAHP, 4; frequency of spin-lock, $400 \mathrm{~Hz}$; and time of spin-lock (TSL), 0, 10, 30, 55, and 90 ms. The total T1 $\rho$ imaging scan time was 1 minute 50 seconds.

Anatomic MR imaging consisted of a minimum of the following: 1) an axial fat-suppressed T2-weigthed turbo spin-echo sequence (TR/TE, 4000/80 ms; FOV, $230 \times 230 \mathrm{~mm}$; section thickness, $4 \mathrm{~mm}$; echo-train length, 15-17; sensitivity encoding factor, 1; number of signals acquired, 2); and 2) an axial T1weighted turbo spin-echo sequence (TR/TE, 500/10 ms; FOV, $230 \times 230 \mathrm{~mm}$; section thickness, $4 \mathrm{~mm}$; echo-train length, 4 ; sensitivity encoding factor, 1; number of signals acquired, 2). The patients with NPC were also scanned using a T1-weighted turbo spin-echo sequence following a bolus injection of $0.1 \mathrm{mmol}$ of gadoteric acid (Dotarem; Guerbet) per kilogram of body weight.

\section{Imaging Analysis}

T1 $\rho$ images were reconstructed at a matrix size of $288 \times 288$. These images were used for T $1 \rho$ quantification using an in-house Matlab (MathWorks) program. The images were smoothed by a sliding $2 \times 2$ window throughout the image before quantification. At each pixel, the image intensity was fitted to the relaxation model $y=A \times \exp \left(-\frac{T S L}{T 1 r h o}\right)+B$ to calculate the T1 $\rho$ value, where $A$ and $B$ are 2 unknown constants. We used a variant of the dichotomy method $^{25}$ to fit the data to this relaxation model to quantify T1 $\rho$ values. For on-resonance spin-lock, the $B$ term is positive. This condition was incorporated into the fitting algorithm to improve fitting accuracy. The peak signal-to-noise ratio (PSNR) was calculated to evaluate the goodness of fit. The definition of PSNR is

$$
\operatorname{PSNR}=10 \times \log { }_{10}\left(\frac{N \times \max _{i}\left(y_{i}-\bar{y}\right)^{2}}{\sum_{i=1}^{N}\left(y_{i}-\hat{y}_{i}\right)^{2}}\right),
$$

where $y_{i}, \bar{y}, N$, and $\hat{y}_{i}$ are the raw data, their mean, their number, and their fitted values, respectively. Criteria were set to exclude pixels with obvious errors or possible unreliable fitting results. A pixel was excluded from final analysis if it had a PSNR of $<30$ or an extreme T $1 \rho$ value ( $<15 \mathrm{~ms}$ or $>200 \mathrm{~ms}$ ).

The walls and/or adenoid of benign hyperplasia (Fig 1A) and the primary NPC (Fig $1 B$ ) were contoured manually, excluding obvious necrotic, cystic, or hemorrhagic areas, with reference to the corresponding anatomic images (Fig 1C, -D). The normal brain (cerebellum), muscle (lateral pterygoid muscle), and parotid gland were also manually contoured in 41 participants with benign hyperplasia. Contouring was performed by a researcher with 5 years' experience in MR imaging of NPC and repeated after an interval of 2 weeks (observer 1 ) and by a diagnostic radiologist with 1-year postfellowship experience in head and neck imaging (observer 2). The mean, SD, skewness, and kurtosis were calculated from the histogram of the T1 $\rho$ map (Fig $1 E,-F)$.

\section{Statistical Analysis}

T1 $\rho$ measurements of NPC were compared with those of benign hyperplasia in the nasopharynx and with those of normal tissue using the Mann-Whitney $U$ test. Subgroup analysis was performed to assess the differences in T1 $\rho$ measurements between stage T1 NPC and stage T2-4 NPC using the Mann-Whitney $U$ test. Receiver operating characteristic curve analysis and area under the curve (AUC) calculations of statistically significant T $1 \rho$ measurements were used to identify the optimal thresholds for discriminating NPC and benign hyperplasia by maximizing the sensitivity plus specificity; the statistically significant of these optimal thresholds was re-evaluated with the $\chi^{2}$ test. The sensitivity, specificity, positive predictive value, negative predictive value, and accuracy of the optimal thresholds were calculated, and the AUCs were compared using the Delong test. ${ }^{26}$ Differences in the T1 $\rho$ measurements of normal brain and muscle and the parotid gland were compared using the analysis of variance test, and for statistically significant differences, the Fisher least significant difference test was then used for post hoc multiple comparisons. These analyses used the average values of the measurements obtained from the 2 observers.

Intraclass correlation coefficients with $95 \%$ confidence intervals were calculated to assess the intra- and interobserver agreement for T1 $\rho$ measurements. Intraclass correlation coefficients of $\leq 0.20,0.21-0.40,0.41-0.60,0.61-0.80$, and $0.81-1.00$ indicated slight, fair, moderate, substantial, and almost perfect agreement, respectively. ${ }^{27}$ All of the statistical tests were 2 -sided, and a $P$ value 

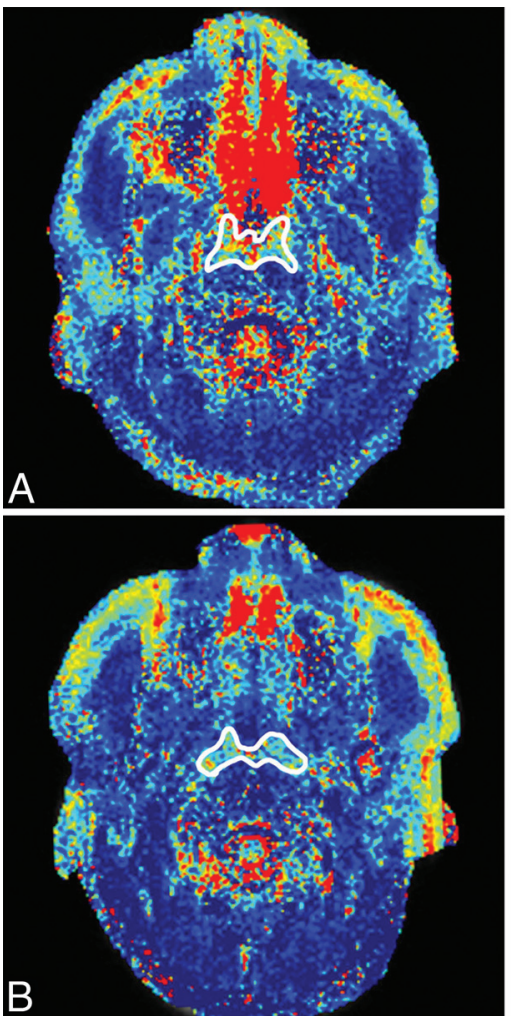
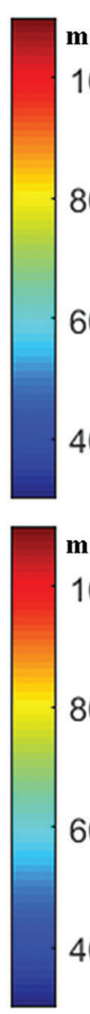
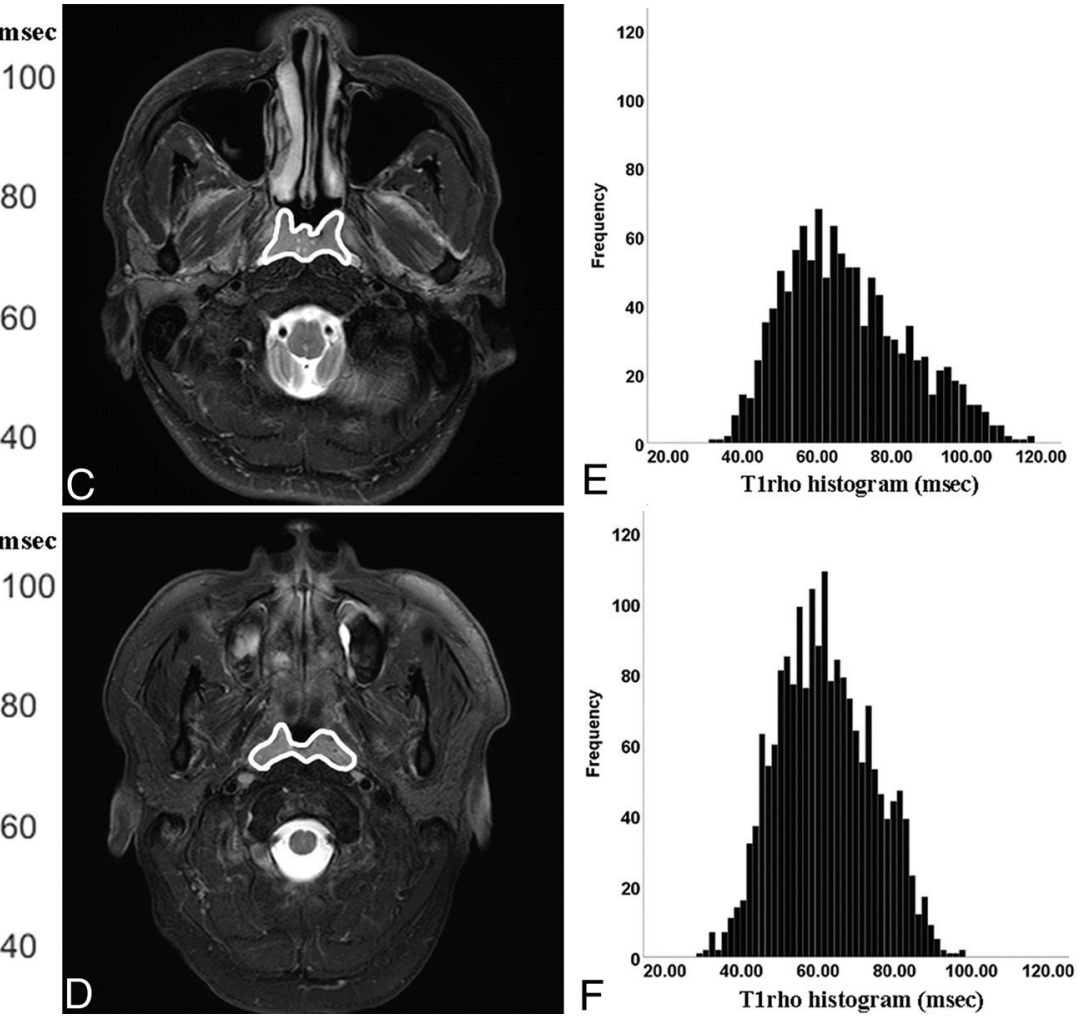

FIG 1. The T1rho maps $(A$ and $B)$ and histograms $(C$ and $D)$ of a participant with benign hyperplasia $(A$ and $C)$ and a participant with NPC $(B$ and $D)$, respectively. Compared with participant with benign hyperplasia, the participant with NPC had a lower Tlrho mean (70.92 versus 61.96 ms), T7rho SD (16.75 versus $13.30 \mathrm{~ms}$ ), and T7rho skewness ( 0.62 versus 0.47$)$.

Table 1: Characteristics of 43 participants with NPC and 41 participants with benign hyperplasia in the nasopharynx

\begin{tabular}{lcc}
\multicolumn{1}{c}{ Clinical Characteristics } & $\begin{array}{c}\text { Patients with NPC } \\
(\boldsymbol{n}=\mathbf{4 3})\end{array}$ & $\begin{array}{c}\text { Patients with Benign } \\
\text { Hyperplasia }(\boldsymbol{n}=\mathbf{4 1})\end{array}$ \\
\hline Age (yr) & $53(33-83)^{\mathrm{a}}$ & $54(41-66)^{\mathrm{a}}$ \\
Median & $54.5 \pm 10.5$ & $53.6 \pm 6.9$ \\
Mean \pm SD & & 41 \\
Sex & 31 & 0 \\
Men & 12 & NA \\
Women & 14 & NA \\
Primary tumor invasion & 29 & \\
Deep invasion absent (stage T1) & & \\
Deep invasion present (stages T2-4) & & \\
\hline
\end{tabular}

Note:-NA indicates not applicable.

${ }^{a}$ Data in parentheses indicate the range.

$<.05$ was considered a statistically significant difference. Analyses were performed using MedCalc statistical software (Version 14.8.1; MedCalc Software) and SPSS (Version 25.0; IBM).

\section{RESULTS}

\section{Participants}

Forty-three participants with NPC and 41 participants with benign hyperplasia were recruited for analysis. The characteristics of each group are shown in Table 1. NPCs were staged to T1, T2, T3, and T4 in 14, 12, 12, and 5 participants, respectively. Participants with benign hyperplasia showed no evidence of NPC at follow-up (median, 15.0 months; range, 7.5-19.4 months).

\section{Tl $\rho$ Imaging in Normal Tissue, NPC, and Benign Hyperplasia in the Head and Neck}

T1 $\rho$ measurements of NPC, benign hyperplasia, and normal tissue (brain, muscle, and parotid gland) are shown in On-line Table 1. Compared with benign hyperplasia, the T1 $\rho$ mean, $\mathrm{SD}$, and skewness of NPC were lower (all, $P<.01)$ (On-line Table 1 and Fig $2 A-C)$, but there was no difference in kurtosis $(P=.18)$ (On-line Table 1 and Fig $2 D$ ). T1 $\rho$ maps with the contours and histograms of a participant with benign hyperplasia and NPC are shown in Fig 1. There were no differences in T1 $\rho$ mean, $\mathrm{SD}$, skewness, and kurtosis between stage $\mathrm{T} 1$ and $\mathrm{T} 2-\mathrm{T} 4$ NPCs (all, $P>$.05) (Table 2). Compared with normal tissue, the T1 $\rho$ means of NPC were lower than those of brain and higher than those of muscle and the parotid gland (all, $P<.001$ ), and the T1 $\rho$ SD of NPC was higher than all 3 normal tissues (all $P<$.001) (On-line Table 1). For the normal tissues, differences in T1 $\rho$ measurements between any of the 2 normal tissues were statistically significant (all, $P<.05$ ).

The intra- and interobserver agreement for T1 $\rho$ measurements is shown in On-line Table 2. The highest intra- and interobserver agreement was found for the T1 $\rho$ mean (intraclass correlation coefficients $=0.99$ and 0.99 , respectively) and for the 

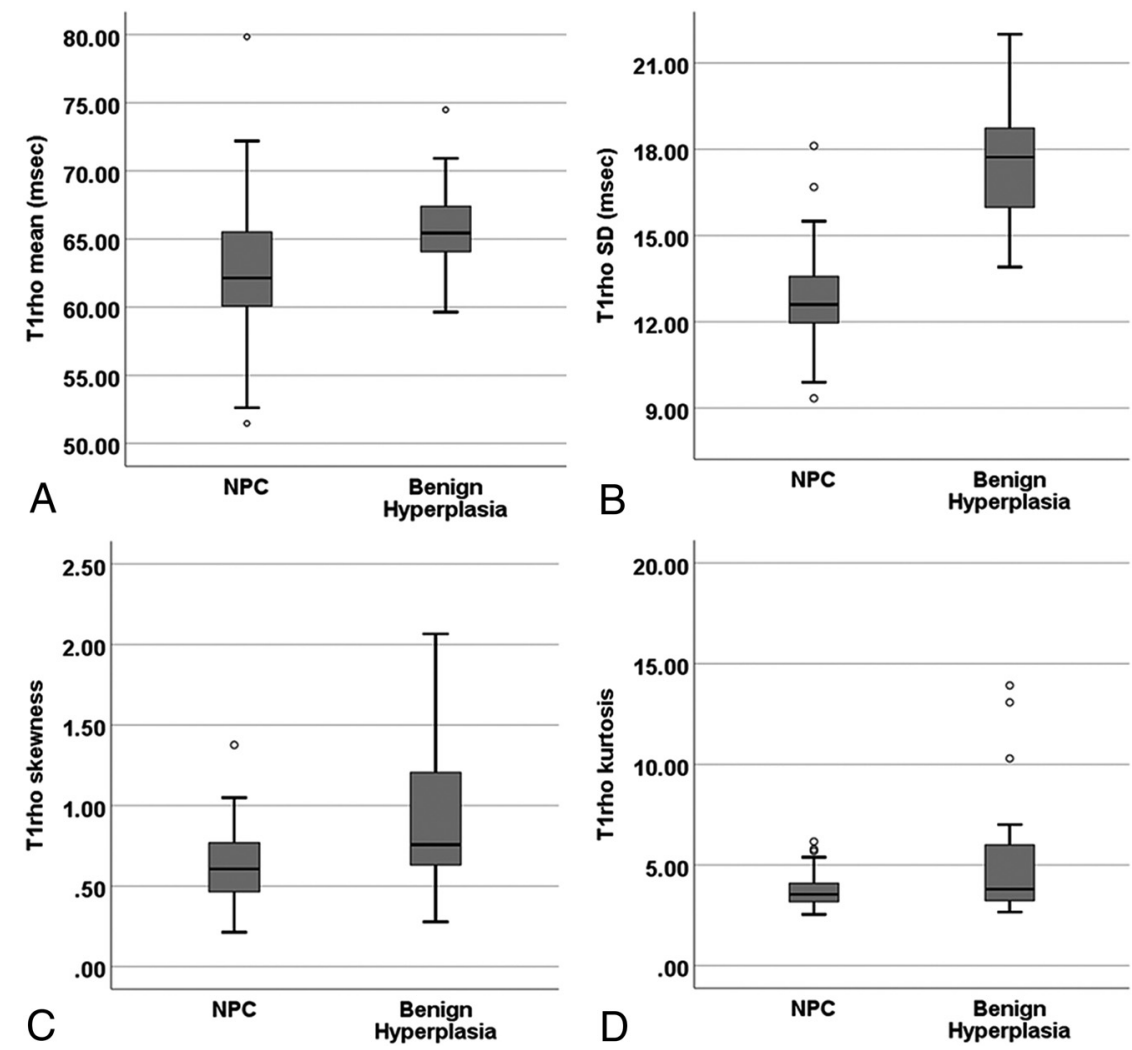

FIG 2. Boxplots of the T1rho mean (A), T7rho SD (B), T7rho skewness (C), and T7rho kurtosis $(D)$ in participants with benign hyperplasia and NPC. Boundaries of boxes closest to and furthest from $0 \mathrm{~ms}$ indicate the 25th and 75th percentiles, respectively. The line within each box indicates median values. Error bars indicate the smallest and largest values within 1.5 box lengths of the 25th and 75th percentiles. Individual points indicate outliers. Compared with participants with benign hyperplasia, participants with NPC had a lower T1rho mean (A), T7rho SD (B), and T7rho skewness $(C)$ (all, $P<.01$ ). There were no differences between the 2 groups for Tlrho kurtosis $(D)(P=.18)$.

Table 2: $\mathrm{T1} \rho$ measurements in stage $\mathrm{T1}$ and $\mathrm{T} 2-4 \mathrm{NPC}^{\mathrm{a}}$

\begin{tabular}{lccc}
\hline T1rho Measurements & Stage T1 NPCs $(\boldsymbol{n}=14)$ & Stage T2-4 NPCs $(\boldsymbol{n}=29)$ & $\boldsymbol{P}$ Value \\
\hline Mean (ms) & $61.94(59.18-64.51)$ & $62.14(60.23-66.56)$ & .31 \\
SD (ms) & $12.48(11.75-14.21)$ & $12.62(11.91-13.88)$ & .92 \\
Skewness & $0.59(0.39-0.78)$ & $0.61(0.48-0.77)$ & .57 \\
Kurtosis & $3.10(2.89-3.92)$ & $3.38(3.02-4.16)$ & .08 \\
\hline
\end{tabular}

${ }^{a}$ Data are median values; data in parentheses are interquartile range. $P$ values $<.05$ indicate statistical significance.

Table 3: Diagnostic performance of $\mathrm{Tl} \rho$ imaging for detecting malignancy of NPC from nasopharyngeal benign hyperplasia ${ }^{a}$

\begin{tabular}{lccc}
\hline & Tlrho Mean & Tlrho SD & Tlrho Skewness \\
\hline AUC & $0.72(0.60-0.81)$ & $0.95(0.88-0.99)$ & $0.72(0.61-0.81)$ \\
$P$ value & .001 & .001 & .001 \\
Threshold & $\leq 62.70 \times \mathrm{ms}$ & $\leq 14.50 \times \mathrm{ms}$ & $\leq 0.57$ \\
Sensitivity (\%) & 58.1 & 88.4 & 48.8 \\
Specificity (\%) & 90.2 & 95.1 & 90.2 \\
PPV (\%) & 86.2 & 95.0 & 84.0 \\
NPV (\%) & 67.3 & 88.6 & 62.7 \\
Accuracy (\%) & 73.8 & 91.7 & 69.0 \\
\hline
\end{tabular}

Note:-PPV indicates positive predictive value; NPV, negative predictive value

${ }^{a}$ Unless otherwise indicated, data in parentheses are $95 \%$ confidence intervals. $P$ values $<.05$ indicate statistical significance.
T1 $\rho$ SD (intraclass correlation coefficients $=0.98$ and 0.96 , respectively).

Diagnostic Performance of $\mathrm{Tl} \rho$ Measurements for Discriminating NPC and Benign Hyperplasia

The AUC, optimal threshold, and diagnostic performance of statistically significant T $1 \rho$ measurements for discriminating between NPC and benign hyperplasia are shown in Table 3. The T1 $\rho$ SD showed the highest AUC of 0.95 compared with the T1 $\rho$ mean $(\mathrm{AUC}=0.72)$ and $\mathrm{T} 1 \rho$ skewness $($ AUC $=0.72)($ all, $P<.001$, Table 3 and Fig 3). The T $1 \rho$ SD of $\leq 14.50 \mathrm{~ms}$ achieves a sensitivity of $88.4 \%$, specificity of $95.1 \%$, positive predictive value of $95.0 \%$, negative predictive value of $88.6 \%$, and accuracy of $91.7 \%$ for discriminating NPC from benign hyperplasia.

\section{DISCUSSION}

In this preliminary study, we evaluated the capability of this new quantitative T1 $\rho$ MR imaging sequence for head and neck cancer imaging to discriminate malignant tissue, specifically NPC from benign tissue in the nasopharynx and from surrounding normal tissue. In keeping with a previous study published in $1998,{ }^{11}$ the T1 $\rho$ mean varied between different normal tissues, being higher in brain, followed by in the parotid gland and muscle. Compared with these normal tissues, the T1 $\rho$ mean of NPC was lower than that of the brain but higher than that of the parotid gland and muscle. Moreover, the T1 $\rho$ mean of NPC was statistically significantly lower than that of the benign hyperplasia. Factors in the head and neck that influence T1 $\rho$ values are unclear, but previous phantom and in vivo musculoskeletal studies have reported that the T1 $\rho$ value is negatively associated with the macromolecule content and positively associated with water content. ${ }^{28-30}$ Therefore, the overexpression of macromolecular proteins could be contributing to the low T1 $\rho$ mean values in NPC, while higher water content in the inflammation could be contributing to the high mean T1 $\rho$ values in benign hyperplasia.

We further analyzed measurements other than the T1 $\rho$ mean from the

2342 Ai Dec 2020 www.ajnr.org 


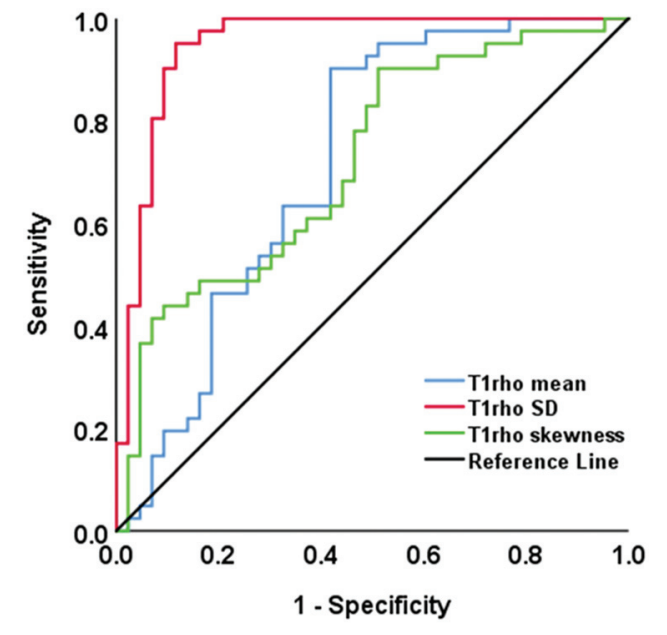

FIG 3. The receiver operating characteristic curves of T7rho mean (blue curve), T7rho SD (red curve), and T7rho skewness (green curve) for discriminating NPC and benign hyperplasia in the nasopharynx. The Thrho SD showed the highest AUC of 0.95 compared with the Tlrho mean (AUC $=0.72$ ) and Thrho skewness (AUC $=0.72)(P<.05)$ for distinguishing NPC from benign hyperplasia.

T1 $\rho$ histogram and found that T1 $\rho$ SD and skewness were lower in NPC than in benign hyperplasia, with low values indicating NPC but higher values being unable to discriminate these 2 entities. Of all these measurements, the SD achieved the highest AUC. The lower T1 $\rho$ SD in NPC compared with benign hyperplasia suggests that this cancer is less heterogeneous than inflammation. The use of the optimal T1 $\rho$ SD showed a high positive predictive value, suggesting that the potential role of T1 $\rho$ imaging could be to minimize false-positive findings and hence reduce the number of patients referred unnecessarily for further examinations. The intraclass correlation coefficients were high for all T1 $\rho$ measurements with the exception of kurtosis, which had a low intraclass correlation coefficient and was the only T1 $\rho$ measurement that did not show a difference between the 2 groups.

A potential future role for T1 $\rho$ imaging in the nasopharynx is for MR imaging screening of NPC. MR imaging detects 10\%$17 \%$ more NPCs than an endoscopic examination, ${ }^{31-33}$ but discrimination of early-stage NPCs is confined to the nasopharynx (stage T1), and benign hyperplasia can be problematic on anatomic-based MR imaging sequences when the cancer involves both sides of the nasopharynx symmetrically. ${ }^{19,20,34}$ The results of the current study are encouraging because we found differences in T1 $\rho$ measurements between NPC and benign hyperplasia. Furthermore, there were no differences in the T1 $\rho$ values of stage T1 and T2-4 NPCs, so it is probable that these results could be applied to a screening population with early-stage disease. However, future studies are needed to validate the findings, evaluate optimal thresholds, and determine whether T1 $\rho$ imaging can improve on the diagnostic performance of anatomic MR imaging sequences in NPC detection.

One advantage of using T $1 \rho$ imaging in MR imaging screening is that it does not require extra hardware or an intravenous injection of contrast. These advantages also apply to diffusion-weighted imaging, which is another functional MR imaging sequence that has shown promise in the discrimination of malignant and benign tissue in the head and neck. ${ }^{35-37}$ However, susceptibility artifacts can limit the application of diffusion-weighted imaging. ${ }^{35}$ This image distortion can be mitigated by a fast spin-echo acquisition, but this results in significant loss of signal-to-noise-ratio efficiency compared with an echo-planar imaging acquisition, often leading to a longer scan time. On the other hand, there is less image distortion from $\mathrm{B}_{0}$ field inhomogeneities in T1 $\rho$ imaging. This is achieved using an adiabatic continuous wave constant amplitude spin-lock to ensure that all spins are well-locked along the effective spin-lock field, even in the presence of $B_{1}$ radiofrequency and $B_{0}$ field inhomogeneities. ${ }^{22,23}$

This study had several limitations. First, it did not correlate T1 $\rho$ imaging with biologic characteristics, so the underlying biologic factors contributing to the T1 $\rho$ values in the head and neck remain unclear. Second, most participants with NPC referred to MR imaging for staging had already undergone a nasopharyngeal biopsy. This scenario is unavoidable, but to minimize the potential influence of a biopsy on the T1 $\rho$ measurement, any foci of hemorrhage were excluded when contouring the primary tumor. Third, while obvious cysts can be excluded from the contoured region, very small cysts of 1-2 mm, which are more commonly seen in benign hyperplasia, cannot be excluded from the analysis. Fourth, this study did not analyze the reproducibility of $\mathrm{T} 1 \rho$ imaging in the head and neck, but previous studies have reported high reproducibility of T1 $\rho$ imaging in other tissue. ${ }^{38,39}$ Furthermore, with an adiabatic continuous wave constant amplitude spin-lock, the spins are locked at a tilted angle from the transverse plane during the spinlock, which results in $\mathrm{T} 1$ contamination of the $\mathrm{T} 1 \rho$ measurements. ${ }^{23}$ The level of $\mathrm{T} 1$ contamination depends on the $\mathrm{B}_{0}$ field inhomogeneities and the $B_{1}$ amplitude of the spin-lock radiofrequency pulse or the frequency of the spin-lock. In our previous study, ${ }^{23}$ we reported that the maximum error of $\mathrm{T} 1 \rho$ quantification due to this effect is within $4 \%$ at a frequency of spin-lock of $500 \mathrm{~Hz}$ and a maximum $\mathrm{B}_{0}$ field inhomogeneity of $100 \mathrm{~Hz}$, but the maximum error at this site is unknown.

\section{CONCLUSIONS}

There are quantitative differences in the T1 $\rho$ measurements of normal, malignant, and benign tissue in the head and neck. T1 $\rho$ imaging, therefore, has the potential to be used to identify malignant tumors. This is a new area for cancer research, and further studies are needed to validate these findings.

Disclosures: Weitian Chen—UNRELATED: Employment: The Chinese University of Hong Kong; Grants/Grants Pending: The Chinese University of Hong Kong*; Patents (Planned, Pending or Issued): a pending US patent and a pending Chinese patient, W. Chen and B. Jiang; System and Method for Continuous Wave Constant Amplitude On-Resonance and Off-resonance Spin-Lock for Magnetic Resonance Imaging, US 15/663,254, US patent, pending; CN 201710649663.X, pending, Comments: no money received;; OTHER RELATIONSHIPS: I am a shareholder of the company lluminatio Medical Technology limited. Wai Kei Jacky Lam—UNRELATED: Patents (Planned, Pending or Issued): patent on clinical applications of circulating DNA*; Stock/Stock Options: Grail. Queenie Chan-UNRELATED: Employment: Queenie Chan is an employee of Philips Healthcare, but she had no control over inclusion of any data or information that might have presented a conflict of interest. There are no actual or potential conflicts of interest to declare in relation to this article. Edwin P. Hui-UNRELATED: Consultancy: Merck Sharp \& Dohme, Comments: Advisory Board; Payment for Lectures Including Service on Speakers Bureaus: Merck Sharp \& Dohme, Merck Serono, Comments: speakers honoraria. K. C. Allen Chan—RELATED: Consulting Fee or Honorarium: Grail; UNRELATED: Board Membership: Take2, DRA; Consultancy: Grail; Grants/Grants Pending: Grail, Cirina*; 
Patents (Planned, Pending or Issued): I am an inventor of over 70 patents; parts of the portfolio have been licensed to Illumina, Grail, Xcelom, DRA; Royalties: Grail, Sequenom, Illumina, Take2, Xcelom; Stock/Stock Options: Grail, DRA, Take2; Travel/Accommodations/Meeting Expenses Unrelated to Activities Listed: Bio-Rad Laboratories. *Money paid to the institution.

\section{REFERENCES}

1. Regatte RR, Akella SV, Wheaton AJ, et al. 3D-T1 $\rho$-relaxation mapping of articular cartilage: in vivo assessment of early degenerative changes in symptomatic osteoarthritic subjects. Acad Radiol 2004;11:741-49 CrossRef Medline

2. Wang YX, Zhao F, Griffith JF, et al. T1 $\rho$ and T2 relaxation times for lumbar disc degeneration: an in vivo comparative study at 3.0Tesla MRI. Eur Radiol 2013;23:228-34 CrossRef Medline

3. Li X, Kuo D, Theologis A, et al. Cartilage in anterior cruciate ligamentreconstructed knees: MR imaging T1 $\rho$ and T2: initial experience with 1-year follow-up. Radiology 2011;258:505-14 CrossRef Medline

4. Haris M, Singh A, Cai K, et al. T1 $\rho$ ( T $1 \rho)$ MR imaging in Alzheimer' disease and Parkinson's disease with and without dementia. J Neurol 2011;258:380-05 CrossRef Medline

5. Magnotta VA, Heo HY, Dlouhy BJ, et al. Detecting activity-evoked pH changes in human brain. Proc Natl Acad Sci U S A 2012;109:8270-73 CrossRef Medline

6. Haris M, McArdle E, Fenty M, et al. Early marker for Alzheimer's disease: hippocampus $\mathrm{T} 1 \rho$ ( T $1 \rho$ ) estimation. J Magn Reson Imaging 2009;29:1008-12 CrossRef Medline

7. Nestrasil I, Michaeli S, Liimatainen T, et al. T1 $\rho$ and T2 $\rho$ MRI in the evaluation of Parkinson's disease. J Neurol 2010;257:964-68 CrossRef Medline

8. Wang YX, Yuan J, Chu ES, et al. T1 $\rho$ MR imaging is sensitive to evaluate liver fibrosis: an experimental study in a rat biliary duct ligation model. Radiology 2011;259:712-19 CrossRef Medline

9. Allkemper T, Sagmeister F, Cicinnati V, et al. Evaluation of fibrotic liver disease with whole-liver $\mathrm{t} 1 \rho \mathrm{MR}$ imaging: a feasibility study at 1.5 T. Radiology 2014;271:408-15 CrossRef Medline

10. Muthupillai R, Flamm SD, Wilson JM, et al. Acute myocardial infarction: tissue characterization with T1 $\rho$-weighted MR imaging: initial experience. Radiology 2004;232:606-10 CrossRef Medline

11. Markkola AT, Aronen HJ, Ramadan UA, et al. Determination of $\mathrm{T} 1 \rho$ values for head and neck tissue at $0.1 \mathrm{~T}$ : a comparison to $\mathrm{T} 1$ and T2 relaxation times. Magn Reson Imaging 1998;16:377-83 CrossRef Medline

12. Zhou N, Chu C, Dou X, et al. Early changes of irradiated parotid glands evaluated by $\mathrm{T} 1 \rho$-weighted imaging: a pilot study. $J$ Comput Assist Tomogr 2017;41:472-76 CrossRef Medline

13. Chu C, Zhou N, Zhang $\mathrm{H}$, et al. Use of T1 $\rho$ MR imaging in Sjögren's syndrome with normal appearing parotid glands: initial findings. J Magn Reson Imaging 2017;45:1005-12 CrossRef Medline

14. Cao M, Ding W, Han X, et al. Brain T1 $\rho$ mapping for grading and IDH1 gene mutation detection of gliomas: a preliminary study. $J$ Neurooncol 2019;141:245-52 CrossRef Medline

15. Aronen HJ, Abo Ramadan U, Peltonen TK, et al. 3D spin-lock imaging of human gliomas. Magn Reson Imaging 1999;17:1001-10 CrossRef Medline

16. Villanueva-Meyer JE, Barajas RF, Mabray MC, et al. Differentiation of brain tumor-related edema based on 3D T1 $\rho$ imaging. Eur $J$ Radiol 2017;91:88-92 CrossRef Medline

17. Santyr GE, Henkelman RM, Bronskill MJ. Spin locking for magnetic resonance imaging with application to human breast. Magn Reson Med 1989;12:25-37 CrossRef Medline

18. Jambor I, Pesola M, Taimen P, et al. Rotating frame relaxation imaging of prostate cancer: repeatability, cancer detection, and Gleason score prediction. Magn Reson Med 2016;75:337-44 CrossRef Medline

19. King $\mathrm{AD}$, Wong $\mathrm{LY}$, Law $\mathrm{BK}$, et al. MR imaging criteria for the detection of nasopharyngeal carcinoma: discrimination of early-stage primary tumors from benign hyperplasia. AJNR Am J Neuroradiol 2018;39:515-23 CrossRef Medline

20. Wang ML, Wei XE, Yu MM, et al. Value of contrast-enhanced MRI in the differentiation between nasopharyngeal lymphoid hyperplasia and T1 stage nasopharyngeal carcinoma. Radiology Med 2017;122:743-51 CrossRef Medline

21. Amin MB, American Joint Committee on Cancer AJCC Cancer Staging Manual. 8th ed. Springer-Verlag; 2017

22. Jiang B, Chen W. On-resonance and off-resonance continuous wave constant amplitude spin-lock and $\mathrm{T} 1 \rho$ quantification in the presence of B1 and B0 inhomogeneities. NMR Biomed 2018;31:1-17 CrossRef Medline

23. Chen W. Artifacts correction for T1 $\rho$ imaging with constant am plitude spin-lock. J Magn Reson 2017;274:13-23 CrossRef Medline

24. Chen W, Chan Q, Wáng YX. Breath-hold black blood quantitative T1 $\rho$ imaging of liver using single shot fast spin echo acquisition. Quant Imaging Med Surg 2016;6:168-77 CrossRef Medline

25. Wilde DJ. Optimum Seeking Methods. Prentice Hal; 1964

26. Delong ER, Delong DN, Clarke-Pearson DL. Comparing the areas under two or more correlated receiver operating characteristic curves: a nonparametric approach. Biometrics 1988;44:837-45 Medline

27. Kundel HL, Polansky M. Measurement of observer agreement. Radiology 2003;228:303-08 CrossRef Medline

28. Ali SO, Fessas P, Kaggie JD, et al. Evaluation of the sensitivity of R $\mathbf{1}$ $\rho$ MRI to $\mathbf{p H}$ and macromolecular density. Magn Reson Imaging 2019;58:156-61 CrossRef Medline

29. Hatcher CC, Collins AT, Kim SY, et al. Relationship between T1 $\rho$ magnetic resonance imaging, synovial fluid biomarkers, and the biochemical and biomechanical properties of cartilage. J Biomech 2017;55:18-26 CrossRef Medline

30. Paul CP, Smit TH, Graaf MD, et al. Quantitative MRI in early intervertebral disc degeneration: $\mathrm{T} 1 \rho$ correlates better than $\mathrm{T} 2$ and ADC with biomechanics, histology and matrix content. PLoS One 2018;13:e0191442 CrossRef Medline

31. King AD, Vlantis AC, Bhatia KS, et al. Primary nasopharyngeal carcinoma: diagnostic accuracy of MR imaging versus that of endoscopy and endoscopic biopsy. Radiology 2011;258:531-37 CrossRef Medline

32. King AD, Vlantis AC, Yuen TW, et al. Detection of nasopharyngeal carcinoma by MR imaging: diagnostic accuracy of MRI compared with endoscopy and endoscopic biopsy based on long-term followup. AJNR Am J Neuroradiol 2015;36:2380-85 CrossRef Medline

33. King AD, Woo JK, Ai QY, et al. Complementary roles of MRI and endoscopic examination in the early detection of nasopharyngeal carcinoma. Ann Oncol 2019;30:977-82 CrossRef Medline

34. King AD, Woo JK, Ai QY, et al. Early detection of cancer: Evaluation of MR imaging grading systems in patients with suspected nasopharyngeal carcinoma. AJNR Am J Neuroradiol 2020;41:515-20 CrossRef Medline

35. Thoeny HC, De Keyzer F, King AD. Diffusion-weighted MR imaging in the head and neck. Radiology 2012;263:19-32 CrossRef Medline

36. Noij DP, Martens RM, Marcus JT, et al. Intravoxel incoherent motion magnetic resonance imaging in head and neck cancer: a systematic review of the diagnostic and prognostic value. Oral Oncol 2017;68:8191 CrossRef Medline

37. Ai QY, King AD, Chan JSM, et al. Distinguishing early-stage nasopharyngeal carcinoma from benign hyperplasia using intravoxel incoherent motion diffusion-weighted MRI. Eur Radiol 2019;29:5627-34 CrossRef Medline

38. Wáng YX, Deng M, Lo GG, et al. Breath-hold black-blood T1 $\rho$ mapping improves liver $\mathrm{T} 1 \rho$ quantification in healthy volunteers. Acta radiol 2018;59:257-65 CrossRef Medline

39. Nemeth A, Di Marco L, Boutitie F, et al. Reproducibility of in vivo magnetic resonance imaging $\mathrm{T} 1$ rho and $\mathrm{T} 2$ relaxation time measurements of hip cartilage at 3.0T in healthy volunteers. J Magn Reson Imaging 2018;47:1022-33 CrossRef Medline 